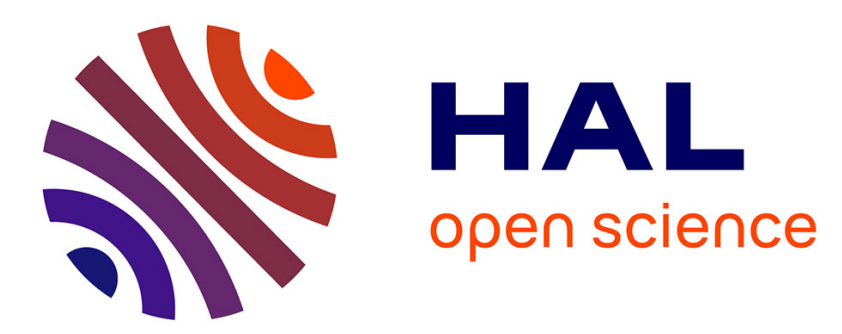

\title{
Effects of Social Influence on Idea Selection in Creativity Workshops
}

\author{
Sylvain Fleury, Aurélien Agnes, Léa Cados, Quentin Denis-Lutard, Clément \\ Duchêne, Nathan Rigaud, Simon Richir
}

\section{- To cite this version:}

Sylvain Fleury, Aurélien Agnes, Léa Cados, Quentin Denis-Lutard, Clément Duchêne, et al.. Effects of Social Influence on Idea Selection in Creativity Workshops. Thinking Skills and Creativity, 2020, 37, pp.100691. 10.1016/j.tsc.2020.100691 . hal-02918237

\section{HAL Id: hal-02918237 \\ https://hal.science/hal-02918237}

Submitted on 2 Sep 2020

HAL is a multi-disciplinary open access archive for the deposit and dissemination of scientific research documents, whether they are published or not. The documents may come from teaching and research institutions in France or abroad, or from public or private research centers.
L'archive ouverte pluridisciplinaire HAL, est destinée au dépôt et à la diffusion de documents scientifiques de niveau recherche, publiés ou non, émanant des établissements d'enseignement et de recherche français ou étrangers, des laboratoires publics ou privés. 


\section{Effects of Social Influence on Idea Selection in Creativity Workshops}

Sylvain Fleury, Aurélien Agnès, Léa Cados, Quentin Denis-Lutard, Clément Duchêne, Nathan Rigaud, Simon Richir

Sylvain.fleury@ensam.eu, Aurelien.agnes@ensam.eu, Lea.cados@ensam.eu, Quentin.denislutard@ensam.eu, Clement.duchene@ensam.eu, Nathan.rigaud@ensam.eu, Simon.richir@ensam.eu

Sylvain Fleury, Ph.D., researcher specialized in cognitive ergonomics at the "Laval Arts et Métiers Institute ». Research engineer at " Presence \& innovation » research team (LAMPA Lab, EA1427) and project manager of the scientific Chaire Time to Concept, his main areas of interests are user experience in virtual reality and methods of innovation.

Aurélien Agnes, M.D., research engineer at the «Laval Arts et Métiers Institute », in the research team Presence \& innovation" (LAMPA Lab, EA1427). He is mainly interested by collaborative working and virtual reality.

Lea Cados, Quentin Denis-Lutard, Clément Duchêne and Nathan Rigaud are Master Degree students specialized in virtual reality at the Laval Institute of ENSAM (Arts \& Métiers).

Simon Richir, M.Eng, Ph.D., one of the pioneers and the most recognized leaders in French VR research and its practical application. Professor at ENSAM (Arts \& Metiers), the renowned French School of Engineering, Simon Richir is also the head of "Laval Arts et Metiers Institute" and "Presence \& innovation" research team (LAMPA Lab, EA1427). His research and teaching activities concentrate on technological innovation, engineering design process, ideation, innovative projects, and innovative uses of new advanced technologies such as Virtual Reality or Augmented Reality. In addition to these activities, he is also the co-founder and the present scientific chair of one of the world's most prestigious international events in Virtual Reality: the annual Laval Virtual International Conference.

Total word count: 5003 


\title{
Effects of Social Influence on Idea Selection in Creativity Workshops
}

\begin{abstract}
Different variants of brainstormings and brainwritings exist and are regularly used in companies. Several phenomena of social influence in the idea generation stage have been highlighted. The hypothesis of this research was that under specific conditions, social influence biases the idea selection stage. An experimental study was conducted with 30 participants who had to select ideas. The results indicate that seeing another person's choice of ideas is enough to influence participants' choices and thus bias their responses. This result is interpreted as the consequence of a phenomenon of social proof: when participants do not know what to choose, they decide to rely on the choice of their partner. Methodological recommendations are provided to avoid this bias during ideation sessions.
\end{abstract}

Keywords : Brainstorming, social influence, ideation, social proof, convergence, idea selection, brainwriting, sticky notes, Innovation, creativity

\section{Introduction}

Brainstorming as we know it was created by Osborn (1957) to improve the emergence of ideas. Brainstorming is divided into 3 phases. The first one: "Preparation" which aims to define the purpose of the Brainstorming, to set up working teams and to organize the meeting. The second phase of brainstormings is called "The animation". This phase corresponds to the generation of ideas: this is the phase of divergent creativity. A facilitator should lead and remind the participants of the four basic rules of brainstormings:

- No criticism

- Focus on quantity quantity

- Encourage wild ideas

- Combine and improve ideas

The last phase is "Capitalisation and Valorisation", which aims to reformulate, classify the ideas collected, identify the most relevant ideas and remove unconvincing ideas from further exploitation. This is the convergence phase.

The method has been greatly improved over the years. Numerous research studies have identified methodological points to a greater or lesser extent, improving the performance of these creative workshops. It is known, for example, that in the divergence phase, instructing participants to generate as many ideas as possible within the allotted time leads to an increase in the number of ideas generated (Coskun \& Göçmen, 2019). Similarly, taking breaks helps prevent the decline in the quantity and variability of ideas that would otherwise appear over time in brainstormings (Kohn \& Smith, 2011), focus on evocation of ideas or constraints influence performance (Bonnardel \& Didier, 2020) as well as the six thinking hats technique (Göçmen \& Coskun, 2019). Depending on what we are trying to achieve, we have to organize the ideation workshop with adapted rules. For example, the most original ideas are obtained with a longer thinking time (Acar, Alabbasi, Runco \& Beketayev, 2019) which implies providing longer working sessions.

The collective nature of the brainstorming is based on the hypothesis that the ideas of each participant will help to inspire the other participants who will then be able to build on the ideas previously mentioned. This effect called "cognitive stimulation" has been demonstrated several times and shows that exposure to other ideas increases the generation of ideas by each participant (Dugosh, Paulus, roland \& Yang, 2000; Dugosh \& Paulus, 2005). Many variations of traditional methods have been developed or studied, for example based on the principles of improvised comedy (Hatcher et al., 2018) and humour (Hatcher et al., 2016), sketching (Van Der Lugt, 2002), serious games (Agogué, Levillain \& 
Hooge, 2015 ; Schulz, Geithner, Woalfel \& Krzywinski, 2015), personality traits (Puccio \& Grivas, 2009) or emotions (Yang \& Hung, 2015). Whether we are talking about individual or collective brainstormings, electronic or paper-based ones, brainwriting, brainsketching, the global mechanism remains to start with a phase of divergence, of idea generation, looking rather for quantity and originality, then a convergent phase of organization and selection of ideas.

The progress and effectiveness of brainstormings depends in particular on social influences of various kinds which are played out according to the methodological choices made. Social comparison, originally described by Festinger (1954), can improve the performance of participants if it is appropriately induced. In a study by Coskun and Göçmen (2019), participants generated more written ideas on sticky notes when facilitators told them that after the session, ideas of the participants were going to be looked over to see which one had written the most ideas. Dugosh and Paulus (2005) generated an improvement in idea generation performance by showing other participants ideas on screen, scrolling through the task. This condition makes it possible to generate more ideas than when those same ideas are presented as selected from a database by a computer, because it leads the participants to a situation of social comparison. The induction of social comparison through a form of competition can have beneficial effects and be articulated with the collaboration between the participants (Hutter et al., 2011).

Other forms of social influence can take place in group brainstormings. The performance of people with social anxiety is diminished when they are in a group brainstorming situation (Camacho \& Paulus, 1995). In addition, seeing or hearing the answers of others tends to make the group's responses more similar (Paulus \& Dzindolet, 1993). This effect is similar to the phenomenon of conformism highlighted by Asch (1951) in the sense that the previous responses of the individuals in the group have an effect on the responses of the following individuals, leading to a homogenisation of the responses given. In the case of idea generation, this effect is awkward, as one is looking for significant variability in idea domains. Hearing or seeing the ideas of other participants accentuates the fixation phenomenon (Kohn $\&$ Smith, 2011). In group brainstormings, the most common ideas are the most likely to be shared (Witten-baum \& Park, 2001), as participants tend to show more positive reactions to common ideas than to original ideas (Stasser \& Birchmeier, 2003). This tends to inhibit the most original ideas in a group.

In addition, the presence of a manager, or someone perceived to be in higher authority during an ideation session changes the behaviour of the other members of the group. More specifically, the effect of hierarchy is rather detrimental to the idea generation during the idea generation phase but may be beneficial during the idea selection phase (Keum \& See, 2017).

As a support for the ideation sessions, sticky notes are considered as relevant because of their smallness, cheapness and re-fixability (Ball \& Christensen, 2020). Despite the effectiveness of the sticky notes, some researchers (e.g. Ivanov \& Zelchenko, 2019; Pi, Yang, Hu \& Hong, 2019; Alsaqri \& Al Salmi, 2019; Rickards, 1994) have studied the electronic brainstorming approach in order to facilitate interactions within an ideation group. The interest of this type of tool is to free oneself from the constraints of the number of participants and places, but also to regulate as one wishes the questions of anonymity or the display of the answers of others, with the effects of social influence associated with them. Gallupe et al. (1992) show through a study that electronic brainstorming reduces the effects of blocking production and apprehension on group performance. This effect is all the stronger the larger the groups are. However, even brainstormings based on sticky notes or flipcharts can be practiced individually and then pooled. Thus, the avoidance of certain social effects resultant of the group does not necessarily require the use of electronic tools. Methodological choices can also help control the effects of social influences. 
To better master group effects during divergence, brainwriting techniques can be used (Le Hénaff, Michinov \& Le Bohec, 2018 ; Linsey \& Becker, 2011 ; Litcanu, Prostean, Oros \& Mnerie, 2015) in which individuals, rather than giving their ideas out loud, will instead write them directly on sticky notes or on an individual computer before pooling the ideas.

Brainstormings and group brainwritings remain common methods used in companies (Nutzmann, Sauer, Vob \& Bozkurt, 2019). They aim to lead to projects or solutions that are operational in the long term. Thus, convergence directly following the generation of ideas and aimed at selecting the ideas to be developed is crucial in the process. This can take different forms, but one of the most common is for participants to organize ideas into categories and specify their preference for specific ideas in order to select those that they believe will be retained in the innovation process. A study by VanDamme, Anseel, Duyck and Rietzschel (2019) has shown the existence of a bias during convergence phases. Participants would tend to select ideas based on their feasibility, potentially to the detriment of originality.

At this selection stage, participants are likely to hesitate between several ideas that seem to be of equivalent quality. However, social proof theory indicates that when one hesitates between several choices, there is a natural tendency to opt for the choice most made by one's peers (Cialdini, 2001). According to this theory, what other people do provides quick and useful information for decision making. It is both a social influence phenomenon that operates in different contexts and an influence technique used in marketing. All other things being equal, the posting of a high number of likes (up to a certain point ; De Vries, 2019) on social networks, a large number of followers (van Maanen \& van der Vecht, 2013), or learning that a celebrity endorses a product (Apejoyen 2013 ; Jain, 2011) are considered to be factors that increase the consumers' purchasing intention of a product (Talib \& Saat, 2017). Social proof can also be used to promote behaviours other than purchasing, such as reducing trolling on the Internet (Bishop, 2015), to reduce the bias of complacency when answering scientific study questionnaires (Vashistha, Okeke, Anderson \& Dell, 2018) or to promote the adoption of security tools (Das, Kramer, Dabbish \& Hong, 2015).

In the idea selection stage, depending on the methodology used, it is common for participants to see or hear the choices made by their peers or even their superiors. We hypothesize that during the idea selection stage, participants are influenced by social proof and therefore tend to select the same ideas as their partners. In a more operational way, we assume that participants who have to select their favourite ideas after a peer are more likely to select the same ideas as that peer compared to a situation where participants select their favourite ideas first.

\section{Method}

\subsection{Participants}

The panel is composed of 30 participants ( 21 men and 9 women) students from an engineering school. They are between 21 and 27 years old (mean is 22.73 , standard deviation is 1.60 ). They are familiar with the concept of brainstorming.

\subsection{Material and procedure}

Participants came alone and were first required to read and sign a consent form. The situation presented to the participants was that 6 brainstormings had been carried out by their peers on themes of concern to them ("how to improve training?", " how do you evaluate a student? ", etc.). For each of these 6 brainstormings, 10 sticky notes each containing an idea were pasted on a flipchart, around the written brainstorming question (see figure 1). Participants were confronted with these 6 sheets of flipchart paper one after the other. They then had to designate the three ideas that seemed most relevant to them by sticking a sticker on the three corresponding sticky notes. They also knew they would be deciding along with another peer but did not know that peer was a confederate. 
To be sure that this material would be realistic, it was designed through real brainstorming with students. The confederate, one of the experimenters, also had to designate three ideas for every 10 ideas. On the 6 sets of 10 ideas to be evaluated in this way, the experimenter carried out the evaluation first for 3 of them and the participant carried out the evaluation first for the other 3 . The order of assessments and conditions was balanced. The choices of ideas made by the experimenter were previously fixed in a random way. Since the brainstorming topics directly concerned the participants, the task was presented as an evaluation of brainstorming ideas to improve the training. The condition of evaluating ideas was presented as an effective method of proceeding.

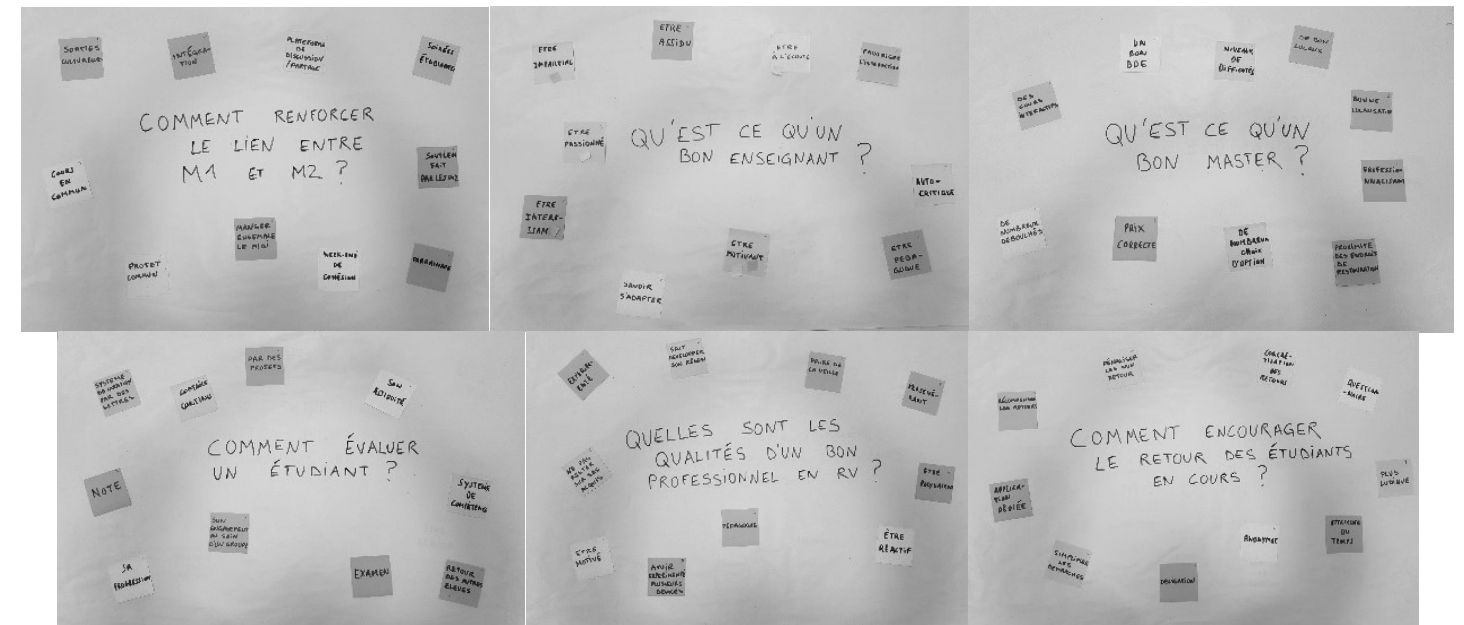

Figure 1: The 6 panels presented to the participants and on which they had to select their 3 most relevant ideas in their opinion

For this step, the number of common choices was measured, i.e. sticky notes on which two stickers had been glued, one by the participant and one by the experimenter. Each participant selected a total of 9 sticky ideas in the condition in which he or she first had to select the ideas and a further 9 in the condition in which he or she selected the ideas after the confederate. Each participant therefore has two scores on a scale of zero to nine, representing the number of sticky ideas selected in common with the experimenter in each of the two experimental conditions. Finally, participants were asked whether they thought they had been influenced in their choices.

\section{Results}

The number of common sticky notes between the participants and the experimenter under the two experimental conditions is a numerical variable distributed on a scale from zero to nine. Table 1 presents the set of descriptive indicators for the two groups. As shown below, all indicators (mean, minimum, maximum, median) point towards a superiority of the number of sticky notes in common when the experimenter evaluates first.

Table 1: Descriptive statistics of common sticky notes scores according to experimental conditions

\begin{tabular}{lcc}
\hline & Condition « participant first » & Condition « confederate first » \\
\hline Average & 2.8 & 3.7 \\
Standard deviation & 1.12 & 1.39 \\
Minimum & 0 & 1 \\
Maximum & 5 & 6 \\
Median & 3 & 4 \\
\hline
\end{tabular}

A Shapiro-Wilk normality test showed that this distribution can be considered normal $(\mathrm{W}=.953, \mathrm{p}=$ .206). Thus, the comparison of the means of the two experimental conditions was carried out using a 
T-Test for apparated data. This reveals a statistically significant difference between conditions, $\mathrm{t}(29)=$ $3.203, p=.003$.

Regarding the final question of the experiment, 15 participants said they felt influenced by the experimenter's choices while the other 15 said they did not feel influenced.

\section{Discussion and conclusion}

The objective of this study was to test the hypothesis of a bias related to social influence when brainstorming participants select ideas. In a more operational way, it was a question of checking whether participants who had to select their favourite ideas from a list were influenced by the prior choices of ideas of a peer. The results of the experiment support this hypothesis since there is a statistically significant superiority of the number of ideas selected in common by the participants when they select secondly compared to a control condition in which they selected the ideas first. Since the confederate was actually selecting his "favourite" ideas at random, this result shows an influence of the ideas chosen by the peer on the ideas chosen by the participants. The random choice of ideas by the partner in both experimental conditions neutralize any possible bias due to of the quality of the ideas.

Of the 30 participants interviewed, 15 reported feeling influenced by the choices of the partner. This additional element suggests that the process underlying this influence is conscious, which is consistent with the interpretative hypothesis of social proof. According to this interpretation, participants were sometimes undecided and had difficulty determining their preference among ideas deemed to be equivalent. In this case, they tended to favour ideas that had already been selected by the accomplice.

Out of a total of 9 ideas selected in each experimental condition by each participant, the average number of ideas selected commonly with the partner increases from 2.8 without influence to 3.7 with influence. The "weight" of this bias related to social influence is therefore a little less than one idea on average in this case. This can have several consequences. For example, since this leads participants to choose ideas that are not necessarily their favourites, it may diminish their commitment to the development of those ideas and then to the projects that flow from them in the rest of the process. It is therefore important that the selection of ideas be made in a free and unbiased manner because the participants' adherence to these ideas is important for the future. Moreover, bias in the evaluation and selection of ideas could also lead to the selection of lower quality ideas, or to a convergence of evaluations on a few ideas to the detriment of others.

This bias is therefore not negligible, even more so as the conditions of brainstorming in companies are likely to create an even greater bias. First, the experience led participants to be potentially influenced by only one person, the partner. In a real brainstorming session, there can be many more participants, which can potentially exert an even stronger social influence. In the case of a person who has to select ideas after several participants have positioned themselves, if some form of consensus appears, then the influence may go beyond social proof, but may be akin to conformism, i.e. a form of group pressure. Secondly, we were careful that the conditions of the experiment did not include any authority that could have accentuated the bias. This would have been the case for example with a confederate who was a teacher or simply older than the participants. In the experiment, the partner was a student from the same class as the participants. There was therefore no induction of an image of authority, neither by any staging, nor by the status or the age of the partner. In companies, brainstormings including different professions and different hierarchical levels can be conducted. In these cases, even stronger influence biases can be expected. As Apejoyen (2013) and Jain (2011) shown, social evidence does not exert the same influence depending on the person and the person's suitability for the activity. A movie star specifying that she uses such a beauty product is a more powerful social proof than if she is an unknown person, or not associated with beauty. In the same way, it can be expected that in a 
brainstorming situation on a given topic, participants will grant a certain level of credibility, different for each of the participants regarding the subject dealt with. The notion that if that person chooses that idea, that it must be of quality, is likely to depend on the credibility of the person on the subject. This modulation of social evidence, which is probably very present in companies, will have to be the subject of further studies. Another aspect that may accentuate the effect of social influence in this case is the presence of people from different hierarchical levels. In this case, it is likely that a subordinate will be more strongly influenced by the choices of his or her superior than by those of a colleague at the same level. In this case, the difference would not only be due to the social proof, but also maybe to the authority that could generate a will not to contradict the person or to go in his direction to take care of his own image.

From an application point of view, the results of this experiment lead us to conclude that just as it is important to take social influences into account when organizing the generation of ideas, it is also important to control the social influences that may take place during the idea selection phase. Carrying out this selection with several people together, either out loud or by sticking stickers on the sticky notes of the ideas will generate a social influence that can be rather harmful to the quality of the result of the selection stage. We therefore recommend favouring methods that lead participants to select their preferences without seeing the preferences of others. With paper sticky notes, for example, we can imagine numbering the ideas and each person will write down on an individual sheet the numbers of the ideas he prefers. It is also possible to carry out electronic brainstormings that allow to select ideas without exposing one's choice to everyone, to be shared only in a second step. These electronic brainstormings can for example be based on a 3D environment with avatars for each participant (Buisine \& Guegan, 2019) or on a digitized card game (Lo, Chiang \& Liang, 2013).

In real brainstorming situations, it is usually the same people who carry out the generation of ideas and then the selection of ideas. For this reason, there is a bias towards selecting one's own ideas rather than those of other partners or those that have been discussed most (Tindale, Meisenhelder, DykemaEngblade \& Hogg, 2001). This is the main limitation of our study, as our participants carried out the idea selection stage, but not the pre-generation stage. We made this choice in order to improve the internal validity of the study by ensuring that we have the same ideas for everyone in the panel to be selected. Another possible methodological choice would have been to compare the selection of ideas individually and with two participants. To avoid bias, the selection could have been done alone as well, but by showing the participants what another participant had selected. In our experiment, the selection was made in both conditions with two people, but we only changed the order in which this selection was made. We made this choice because it seemed to us to correspond better to the real uses made in organizations, i.e. a rather collective organization of creativity workshops and rather poorly equipped. The situation in which one person would select ideas individually but see the selections of others seemed unrealistic to us.

The issue of authority effects was excluded from the scope of this study. Nevertheless, it is an important subject for the organization of creative workshops in companies. In the same way as social comparison, which can lead to improvements or reductions in performance, depending on the case, it is possible that the effects due to authority in this context can also be exploited positively by providing a form of stimulation. Future research could be conducted in order to fully understand the effects of authority in the different stages of brainstorming in order to come up with recommendations for the most appropriate tools or methodologies.

\section{References}

Acar, S., Alabbasi, A. M. A., Runco, M. A., \& Beketayev, K. (2019). Latency as a predictor of originality in divergent thinking. Thinking Skills and Creativity, 100574. 
Agogué, M., Levillain, K., \& Hooge, S. (2015). Gamification of creativity: exploring the usefulness of serious games for ideation. Creativity and Innovation Management, 24(3), 415-429.

Alsaqri, R. M., \& Al Salmi, M. N. (2019). The Impact of Using Electronic Brainstorming Strategy in a Blended Learning Environment on Grade-Eleven Female Students' Achievement in Islamic Education in the Sultanate of Oman. Journal of Educational and Psychological Studies [JEPS], 13(3), 516-537.

Apejoye, A. (2013). Influence of celebrity endorsement of advertisement on students' purchase intention. J Mass Communicat Journalism, 3(152), 2.

Asch, S. E. Effects of group pressure on the modificationand distortion of judgments. In H. Guetzkow (Ed.), Groups, leadership, and men. Pittsburgh, Pa.: CarnegiePress, 1951.

Ball, L. J., \& Christensen, B. T. (2020). How sticky notes support cognitive and socio-cognitive processes in the generation and exploration of creative ideas. In Sticky Creativity (pp. 19-51). Academic Press.

Bishop, J. (2015). My click is my bond: The role of contracts, social proof, and gamification for sysops to reduce pseudo-activism and internet trolling. In Gamification: Concepts, Methodologies, Tools, and Applications (pp. 1734-1750). IGI Global.

Bonnardel, N., \& Didier, J. (2020). Brainstorming variants to favor creative design. Applied ergonomics, 83, 102987.

Buisine, S., \& Guegan, J. (2019). Proteus vs. social identity effects on virtual brainstorming. Behaviour \& Information Technology, 1-13.

Camacho, L. M., \& Paulus, P. B. (1995). The role of social anxiousness in group brainstorming. Journal of personality and social psychology, 68(6), 1071.

Cialdini, R. B. (2001). Influence: Science and practice (4th ed.), Boston, MA: Allyn \& Bacon.

Coskun, H., \& Göçmen, Ö. (2019). Individual Brainstorming Performance as a Function of Velocity and Comparison Feedback. Dokuz Eylul University Journal of Graduate School of Social Sciences, 21(1).

Das, S., Kramer, A. D., Dabbish, L. A., \& Hong, J. I. (2015, February). The role of social influence in security feature adoption. In Proceedings of the 18th ACM conference on computer supported cooperative work \& social computing (pp. 1416-1426). ACM.

De Vries, E. L. (2019). When more likes is not better: the consequences of high and low likes-tofollowers ratios for perceived account credibility and social media marketing effectiveness. Marketing Letters, 1-17.

Dugosh, K. L., \& Paulus, P. B. (2005). Cognitive and social comparison processes in brainstorming. Journal of experimental social psychology, 41(3), 313-320.

Dugosh, K. L., Paulus, P. B., Roland, E. J., \& Yang, H. (2000). Cognitive stimulation in brainstorming. Journal of Personality and Social Psychology, 79, 722-735.

Festinger L. (1954). A theory of social comparison processes. Human Relations 1: 117 \pm 140.

Gallupe, R. B., Dennis, A. R., Cooper, W. H., Valacich, J. S., Bastianutti, L. M., \& Nunamaker Jr, J. F. (1992). Electronic brainstorming and group size. Academy of Management Journal, 35(2), 350-369.

Göçmen, Ö., \& Coşkun, H. (2019). The effects of the six thinking hats and speed on creativity in brainstorming. Thinking Skills and Creativity, 31, 284-295. 
Hatcher, G., Ion, W., Maclachlan, R., Marlow, M., Simpson, B., \& Wodehouse, A. (2018). Evolving improvised ideation from humour constructs: A new method for collaborative divergence. Creativity and Innovation Management, 27(1), 91-101.

Hatcher, G., Ion, W., MacLachlan, R., Wodehouse, A., Sheridan, M., \& Simpson, B. (2016, May). Humour processes for creative engineering design. In 14th International Design Conference (Design) (pp. 1015-1024).

Hutter, K., Hautz, J., Füller, J., Mueller, J., \& Matzler, K. (2011). Communitition: The tension between competition and collaboration in community-based design contests. Creativity and innovation management, 20(1), 3-21.

Ivanov, A., \& Zelchenko, P. (2019). Designing an Electronic Brainstorming Environment for Engaging East-Asian Teams. International Journal of Human-Computer Interaction, 1-15.

Jain, V. (2011). Celebrity endorsement and its impact on sales: A research analysis carried out in India. Global Journal of Management and Business Research, 11(4).

Keum, D. D., \& See, K. E. (2017). The influence of hierarchy on idea generation and selection in the innovation process. Organization Science, 28(4), 653-669.

Kohn, N. W., \& Smith, S. M. (2011). Collaborative fixation: Effects of others' ideas on brainstorming. Applied Cognitive Psychology, 25(3), 359-371.

Le Hénaff, B., Michinov, N., \& Le Bohec, O. (2018). Applying the SIDE model to brainwriting: The impact of intergroup comparison and anonymity on creative performance. Journal of Applied Social Psychology, 48(7), 351-359.

Linsey, J. S., \& Becker, B. (2011). Effectiveness of brainwriting techniques: comparing nominal groups to real teams. In Design creativity 2010 (pp. 165-171). Springer, London.

Litcanu, M., Prostean, O., Oros, C., \& Mnerie, A. V. (2015). Brain-writing vs. Brainstorming case study for power engineering education. Procedia-Social and Behavioral Sciences, 191, 387-390.

Lo, L. J., Chiang, C. D., \& Liang, R. H. (2013). HexDeck: Gamification of Tangibles for Brainstorming. Consilence and Innovation in Design-In Procs. of the 5th IASDR, 3165-3175.

Nutzmann, M., Sauer, T., VOß, M., \& Bozkurt, H. (2019). Study on learning concepts applying creativity methods in education and industry. In DS 95: Proceedings of the 21st International Conference on Engineering and Product Design Education (E\&PDE 2019), University of Strathclyde, Glasgow. 12th-13th September 2019.

Osborn, A. F. (1957). Applied imagination. New York: Scribner.

Paulus, P. B., \& Dzindolet, M. T. (1993). Social influence processes in group brainstorming. Journal of Personality and Social Psychology, 64(4), 575.

Pi, Z., Yang, J., Hu, W., \& Hong, J. (2019). The relation between openness and creativity is moderated by attention to peers' ideas in electronic brainstorming. Interactive Learning Environments, 1-9.

Puccio, G., \& Grivas, C. (2009). Examining the relationship between personality traits and creativity styles. Creativity and Innovation Management, 18(4), 247-255.

Rickards, T. (1994). Electronic brainstorming: Asking the right question. Creativity and Innovation Management, 3(2), 110-114. 
Schulz, K. P., Geithner, S., Woelfel, C., \& Krzywinski, J. (2015). Toolkit-based modelling and serious play as means to foster creativity in innovation processes. Creativity and innovation management, 24(2), 323-340.

Stasser, G., \& Birchmeier, Z. (2003). Group creativity and collectivechoice. In P. B. Paulus \& B. A. Nijstad (Eds.), Group creativity: Innovation through collaboration (pp. 85-109). New York: OxfordUniversity Press.

Talib, Y. Y. A., \& Saat, R. M. (2017). Social proof in social media shopping: An experimental design research. In SHS Web of Conferences (Vol. 34, p. 02005). EDP Sciences.

Tindale, R. S., Meisenhelder, H. M., Dykema-Engblade, A. A., \& Hogg, M. A. (2001). Shared cognition in small groups. Blackwell handbook of social psychology: Group processes, 1-30.

Van Damme, M. J., Anseel, F., Duyck, W., \& Rietzschel, E. F. (2019). Strategies to improve selection of creative ideas: An experimental test of epistemic and social motivation in groups. Creativity and Innovation Management, 28(1), 61-71.

Van Der Lugt, R. (2002). Brainsketching and how it differs from brainstorming. Creativity and innovation management, 11(1), 43-54.

van Maanen, P. P., \& van der Vecht, B. (2013, August). An agent-based approach to modeling online social influence. In Proceedings of the 2013 ieee/acm international conference on advances in social networks analysis and mining (pp. 600-607). ACM.

Vashistha, A., Okeke, F., Anderson, R., \& Dell, N. (2018, April). 'You Can Always Do Better!: The Impact of Social Proof on Participant Response Bias. In Proceedings of the $2018 \mathrm{CHI}$ Conference on Human Factors in Computing Systems (p. 552). ACM.

Wittenbaum, G. M., \& Park, E. S. (2001). The collective preference forshared information. Current Directions in Psychological Science, 10,70-73.

Yang, J. S., \& Hung, H. V. (2015). Emotions as constraining and facilitating factors for creativity: Companionate love and anger. Creativity and Innovation Management, 24(2), 217-230. 


\section{Acknowledgement}

This research was conducted within the framework of the Time to Concept scientific and industrial chair. 